\title{
3D fluorescent in situ hybridization using Arabidopsis leaf cryosections and isolated nuclei Leïla Tirichine ${ }^{1,6}$, Philippe Andrey ${ }^{2,3,4,5}$, Eric Biot ${ }^{1}$, Yves Maurin ${ }^{2,3,4}$ and Valérie Gaudin*1
}

\begin{abstract}
Address: ${ }^{1}$ Laboratoire de Biologie Cellulaire, INRA UR 501, IJPB, Route de Saint-Cyr, F-78026 Versailles, France, ${ }^{2}$ Neurobiologie de l'Olfaction et de la Prise Alimentaire, INRA UMR 1197, Domaine de Vilvert, F-78350 Jouy-en-Josas, France, ${ }^{3}$ Université Paris-Sud 11, UMR 1197, F-91400 Orsay, France, ${ }^{4}$ IFR 144 Neuro-Sud, Paris, France, ${ }^{5}$ Université Pierre et Marie Curie, Paris, France and ${ }^{6}$ Institut des Sciences du Végétal, CNRS, avenue de la Terrasse, F-91198 Gif-sur-Yvette, France

Email: Leïla Tirichine - Tirichine@isv.cnrs-gif.fr; Philippe Andrey - Philippe.Andrey@jouy.inra.fr; Eric Biot - Eric.Biot@versailles.inra.fr; Yves Maurin - Yves.Maurin@jouy.inra.fr; Valérie Gaudin* - Valerie.Gaudin@versailles.inra.fr

* Corresponding author
\end{abstract}

Published: 3 August 2009

Plant Methods 2009, 5:II doi:10.1 I86/1746-48|I-5-1।
Received: I May 2009

Accepted: 3 August 2009

This article is available from: http://www.plantmethods.com/content/5/I/II

(C) 2009 Tirichine et al; licensee BioMed Central Ltd.

This is an Open Access article distributed under the terms of the Creative Commons Attribution License (http://creativecommons.org/licenses/by/2.0), which permits unrestricted use, distribution, and reproduction in any medium, provided the original work is properly cited.

\begin{abstract}
Background: Fluorescent hybridization techniques are widely used to study the functional organization of different compartments within the mammalian nucleus. However, few examples of such studies are known in the plant kingdom. Indeed, preservation of nuclei 3D structure, which is required for nuclear organization studies, is difficult to fulfill.

Results: We report a rapid protocol for fluorescent in situ hybridization (FISH) performed on 3D isolated nuclei and thin cryosectioned leaves of Arabidopsis thaliana. The use of direct labeling minimized treatment steps, shortening the overall procedure. Using image analysis, we measured different parameters related to nucleus morphology and overall 3D structure.

Conclusion: Our work describes a 3D-FISH protocol that preserves the 3D structure of Arabidopsis interphase nuclei. Moreover, we report for the first time FISH using cryosections of Arabidopsis leaves. This protocol is a valuable tool to investigate nuclear architecture and chromatin organization.
\end{abstract}

\section{Background}

The organization of chromatin within the cell nucleus has important implications in gene expression. Several studies have aimed to better understand how gene regulation is organized within chromosome territories and how it relates to various level of chromatin folding $[1,2]$. Defining the underlying mechanisms responsible for the positioning and dynamics of various nuclear entities within the nuclear space is a major challenge because it requires the development of specific three-dimensional (3D) tech- niques preserving nuclear integrity and spatial organization.

In mammals, fluorescent in situ hybridization of nuclei with a three-dimensionally preserved organization (3DFISH) has proven to be a useful tool for such studies [3-7]. In plants, 2D-FISH has been widely used to better understand the organization of nuclear components $[8,9]$. Recently, plant 3D-FISH protocols using whole or vibratome-sectioned specimens have been developed [10- 
14]. The most challenging issue for 3D-FISH studies is to preserve the morphology and the structure of the cell nuclei and to minimize nuclear and chromatin modifications during hybridization. Methanol and acetic acid fixation procedures are efficient treatments to eliminate the cytoplasm and thus allow easier penetration of DNA probes. Although widely used in 2D-FISH, these fixative reagents are not suitable for $3 \mathrm{D}$-FISH because they induce nuclear modifications [15]. Furthermore, harsh chemical treatments such as ethanol can alter chromatin organization [16].

Here, we report an alternative protocol for investigating nuclear organization in Arabidopsis nuclei and cryosectioned leaf tissue. To preserve chromatin structure and nuclear morphology, we avoided treatments such as enzymatic digestion, ethanol and heat-dehydration and we reduced thermal denaturation treatments. Using direct labeling, we minimized post-hybridization steps, shortening the procedure and allowing the protocol to be carried out within two days. DAPI counterstaining and digital image analysis assessing nuclear morphological parameters such as volume, compactness and flatness, indicated that this protocol effectively preserves $3 \mathrm{D}$ nuclear structure.

\section{Materials}

Plant material

Arabidopsis thaliana accession Columbia (Col-0) seeds were surface sterilized and grown in vitro at $20^{\circ} \mathrm{C}, 75 \%$ humidity, $60 \mu \mathrm{mol} \mathrm{m} \mathrm{m}^{-2} \mathrm{~s}^{-1}$ and under a 10 hours light/14 hours dark period as described previously [17].

\section{DNA probes}

We used the following DNA clones: 180 bp pAL1 [15], 5S rDNA pCT4.2 [16], 45S rDNA [17], Bacterial Artificial Chromosomes (BAC) T6P5 (GenBank Accession $\underline{\text { AC005970) }}$ and T1J1 (GenBank Accession AF128393), located on small arm of chromosome 2 and 4, respectively. T6P5 and T1J1 belong to the tiling paths of BAC clones selected for chromosome painting: they contain $<5 \%$ of mobile elements and are specific to chromosome 2 and 4 [18]. DNA was extracted using Nucleobond extraction kit (Clontech) according to the manufacturer's instructions.

\section{Reagents and buffers}

Triton X-100.

Dextran sulfate $20 \%$.

RNAse (Sigma AR-6513, stock solution $10 \mathrm{mg} / \mathrm{ml}$ ).

Klenow fragment (40 U/ $\mu \mathrm{l})$ (Invitrogen Y01396).
BioPrime $^{\circledR}$ DNA Labelling System (Invitrogen 18094-011: $2.5 \times$ random primers solution $125 \mathrm{mM}$ Tris- $\mathrm{HCl}(\mathrm{pH}$ 6.8), $12.5 \mathrm{mM} \mathrm{MgCl}_{2}, 25 \mathrm{mM} \beta$-mercaptoethanol, 750 $\mu \mathrm{g} / \mathrm{ml}$ oligodeoxyribonucleotide primers (random octamers) (Invitrogen Y01393).

Fluorochromes: ChromaTide ${ }^{\circledast}$ Alexa Fluor $^{\circledR}$ 488-5-dUTP (Invitrogen C11397), Cy3-dUTP (Amersham PA53022), Cy5-dUTP (Amersham PA55022). Prepare a 10× fluorophore mixture ( $1 \mathrm{mM}$ dATP, $1 \mathrm{mM}$ dCTP, $1 \mathrm{mM}$ dGTP, $0.65 \mathrm{mM}$ dTTP, $0.35 \mathrm{mM}$ fluorochrome).

DAPI (4'6-Diamidino-2-phenylindole) at $1 \mu \mathrm{g} / \mathrm{ml}$ final concentration into VECTASHIELD ${ }^{\circledR}$ antifade mounting medium (Vector Laboratories).

\section{Cryomount medium (Histolab 00890).}

Nuclei extraction buffer (10 mM Tris $\mathrm{HCl} \mathrm{pH} \mathrm{7,} 4 \mathrm{mM}$ spermidine, $1 \mathrm{mM}$ spermine, $5 \mathrm{mM} \mathrm{MgCl}_{2}, 0.1 \%$ triton $\mathrm{X}$ 100).

1× Phosphate-Buffered Saline (PBS) $\mathrm{pH} 7.3$ (3.2 mM $\left.\mathrm{Na}_{2} \mathrm{HPO}_{4}, 0.5 \mathrm{mM} \mathrm{KH}_{2} \mathrm{PO}_{4}, 135 \mathrm{mM} \mathrm{NaCl}, 1.3 \mathrm{mM} \mathrm{KCl}\right)$.

$20 \times \operatorname{SSC}(3 \mathrm{M} \mathrm{NaCl}, 0.3 \mathrm{M}$ sodium citrate, $\mathrm{pH} 7.0)$.

Stop buffer 0.5 M Na 2 EDTA pH 8.0 (Invitrogen 50690).

HB50 (50\% deionized formamide, $2 \times$ SSC, $50 \mathrm{mM}$ phosphate, $\mathrm{pH} 7.0)$.

\section{Equipment}

Vacuum pump.

Centrifuge Sigma 3K18 rotor 11133.

Nanodrop, Labtech spectrophotometer ND-1000.

Hot plate $\left(75-80^{\circ} \mathrm{C}\right)$ and heating block $\left(100^{\circ} \mathrm{C}\right)$.

Incubators $\left(37^{\circ} \mathrm{C}\right.$ and $\left.55^{\circ} \mathrm{C}\right)$ and a moist chamber.

Coplin jars.

Silanized slides (Dako S3003) or SuperFrost ${ }^{\circledR}$ Plus glass slides (Menzel-Gläser J1800AMNZ).

Coverslips $(22 \times 22$ and $24 \times 50 \mathrm{~mm})$.

Dako pen (Dako S2002).

Cryostat (Leica CM-3050S). 


\section{FISH Protocol}

\section{Fixation}

Fix young seedlings (18 days-post-germination) in 4\% paraformaldehyde (PFA) in $1 \times$ PBS buffer at room temperature (RT) for 30 minutes under a vacuum. Replace the fixative solution with fresh fixative solution and fix for an additional 30 minutes under a vacuum. Rinse seedlings in $1 \times$ PBS twice for 5 minutes each and store in $1 \times$ PBS at $4^{\circ} \mathrm{C}$ until use (fixed seedlings can be stored for up to a month).

\section{Nuclei extraction}

The extraction protocol is based on the existing protocol reported by [19]. All centrifugation steps were carried out

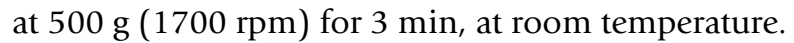

Place up to 8 seedlings in a $1.5 \mathrm{ml}$ Eppendorf tube containing $500 \mu \mathrm{l}$ of nuclei extraction buffer. Prior to extraction, add $\beta$-mercaptoethanol to a final concentration of 5 $\mathrm{mM}$. Extract nuclei gently with a plastic pestle. Filter the nuclei suspension through a $50 \mu \mathrm{m}$ nylon mesh. Discard the supernatant after centrifugation and wash the pellet with $1 \times$ PBS. Treat the pellet with $300 \mu \mathrm{l}$ of $1 \times$ PBS containing $0.5 \%$ triton $\mathrm{X}-100$ for 5 minutes. Centrifuge, discard the supernatant and wash the pellet with $1 \times$ PBS for 3 minutes.

Resuspend the pellet in $30 \mu \mathrm{l}$ of $1 \times$ PBS. Add $4 \mu \mathrm{l}$ of this suspension to a slide and dry the slide at $4{ }^{\circ} \mathrm{C}$ for 20 minutes before mounting with DAPI or carrying on with the FISH procedure. Draw a circle around the drop of nuclei on the slide using a DAKO pen to avoid deforming the specimen once mounted with a coverslip.

\section{Cryostat sectioning}

To prepare tissue for cryostat sectioning, cut leaves into small pieces (about $5 \mathrm{~mm}^{2}$ ) and incubate the leaf sections in $15 \%$ sucrose overnight at $4^{\circ} \mathrm{C}$. Place a piece of leaf on a slide, remove the excess of sucrose and add to the leaf a drop of mounting medium. Transfer the slide to a cryostat chamber maintained at $-25^{\circ} \mathrm{C}$ during sectioning and leave the slide within the cryostat chamber until the mounting medium and leaf sample are frozen. Remove the frozen sample from the slide with forceps and transfer it to a mounting stub in an upright position for transversal sectioning. Add few $\mu$ l of mounting medium and correct the orientation of the sample being careful to maintain it in an upright position until the mounting medium freezes.

To section the tissue, transfer the sample to the holder and adjust the orientation of the sample, the microtome knife and the anti-roll plate. For FISH studies, we used 10, 16 and $20 \mu \mathrm{m}$ sections. After sectioning, carefully place the leaf sections on a SuperFrost or silanized slide that has been pre-cooled to $-25^{\circ} \mathrm{C}$. The sample can be stored on the slide at $-20^{\circ} \mathrm{C}$ until use. Let the slide thaw at room temperature before washing in $1 \times$ PBS for 5 minutes to remove the mounting medium.

\section{Pretreatments and prehybridization}

Incubate leaf sections with $1 \times$ PBS containing $0.5 \%$ triton $\mathrm{X}-100$ for 10 minutes or incubate isolated nuclei with $1 \times$ PBS containing $0.5 \%$ triton for 3 minutes at RT. Wash the slide with $1 \times$ PBS for 5 minutes to remove the detergent and proceed to the $\mathrm{HCl}$ treatment. Treat leaf sections with sterile water containing $0.1 \mathrm{~N} \mathrm{HCl}$ for 20 minutes at RT. Rinse the slide with sterile water for 5 minutes and proceed directly to the RNase treatment. For the RNase treatment, equilibrate the slide in $2 \times$ SSC for 5 minutes at RT then incubate the slide in $2 \times$ SSC containing $400 \mu \mathrm{g} / \mu \mathrm{l}$ RNase for 15 minutes in a moist chamber at $37^{\circ} \mathrm{C}$. Rinse the slide in $2 \times$ SSC for 2 minutes at RT. Apply the HB50 prehybridization mixture $(\sim 100 \mu \mathrm{l})$ to the slide, place a coverslip over the sample and incubate it in a moist chamber at $37^{\circ} \mathrm{C}$ for 1 to 2 hours.

\section{Random primer probe labeling}

On ice, add $20 \mu \mathrm{l}$ of $2.5 \times$ random primers solution to 20 $\mu \mathrm{l}$ DNA (100 ng). Denature this mix at $100^{\circ} \mathrm{C}$ for $10 \mathrm{~min}-$ utes and immediately cool it on ice. Add $5 \mu$ l of fluorochrome mixture and distilled water to a total volume of 49 $\mu \mathrm{l}$. After a brief vortexing, add $1 \mu \mathrm{l}$ of klenow enzyme. Mix gently by pipetting up and down and centrifuge the reaction for 30 seconds. Incubate the reaction at $37^{\circ} \mathrm{C}$ for 1 hour to yield 100 to 200 base pairs (bp) fragments. Load $5 \mu \mathrm{l}$ of the reaction on a $1 \%$ agarose gel to verify the length of the DNA fragments. If the DNA length is not between 100 and $200 \mathrm{bp}$, incubate for an additional hour or up to 24 hours. Stop the reaction, by adding $5 \mu$ l of stop buffer and store the probe at $-20^{\circ} \mathrm{C}$ until use.

\section{Hybridization}

Prepare the probe mix as follows: $10 \mu \mathrm{l}$ of $20 \%$ dextran sulfate, 1 to $9 \mu$ l HB50 (50\% deionized formamide in $2 \times$ SSC and $50 \mathrm{mM}$ sodium phosphate, $\mathrm{pH} 7.0$ ), 1 to $9 \mu \mathrm{l}$ of probe and adjust to a final volume of $20 \mu \mathrm{l}$. Use 100 to $400 \mathrm{ng}$ of DNA for BAC clones and 20 to $100 \mathrm{ng}$ of DNA for repeated DNA. Denature the probe at $100^{\circ} \mathrm{C}$ for 5 minutes and transfer immediately to ice.

Denature the sample at $75^{\circ} \mathrm{C}$ for 5 minutes, drain from the denatured slide any excess fluid, and add $20 \mu \mathrm{l}$ of denatured probe to the sample. Cover the sample with a coverslip and hybridize it in a moist chamber at $37^{\circ} \mathrm{C}$ for 2 to 3 hours or overnight for convenience.

\section{Post-hybridization washes and detection}

Wash sample as follows: 2 washes in $2 \times$ SSC for 15 minutes each at $55^{\circ} \mathrm{C}$; 1 wash in $1 \times$ SSC for 10 minutes at $55^{\circ} \mathrm{C}$ and 1 wash in sterile water for 2 minutes at RT. 
Mount the slide in $3 \mu \mathrm{l}$ of Vectashield containing $1 \mu \mathrm{g} / \mathrm{ml}$ DAPI. Seal the coverslip with colorless nail polish and store at $4{ }^{\circ} \mathrm{C}$ (sealed samples can be stored up to a month at $\left.4^{\circ} \mathrm{C}\right)$.

\section{Microscopy and image acquisition}

All images were taken with a Leica DMIRE2 SP2 confocal microscope (Leica Microsystems, Heidelberg, Germany). A UV diode (405 nm) was used for DAPI visualization and three lasers at $488 \mathrm{~nm}, 543 \mathrm{~nm}$ and $633 \mathrm{~nm}$ were used for the excitation of Alexa Fluor ${ }^{\circledast} 488-5-d U T P$, Cy3-dUTP and Cy5-dUTP, respectively. Images were taken through a $63 \times$ water immersion objective (NA 1.2, WD $0.2 \mathrm{~mm}$ ). Z series images were collected at $0.120 \mu \mathrm{m}$ intervals. Images were scanned with a zoom of 9.29, a frame average of 2 and a line average of 2 .

\section{Image processing and analysis}

To investigate the impact of the FISH treatments on nucleus morphology, confocal images of DAPI stained nuclei were acquired before and after FISH. Leaf nuclei of untreated cryosections were used as a reference. After automatic extraction of nucleus masks from the confocal images, morphometrical parameters of the three nucleus classes were extracted and compared.

\section{Nucleus image segmentation}

Confocal image stacks were automatically converted to a format enabling their processing by programs developed using the Free-D software libraries [20]. To separate the nucleus from the background, a preliminary intensity threshold was computed using the isodata algorithm [21]. Since this algorithm is sensitive to the relative size of the nucleus within the image, the threshold was generally too high because of the larger background size. This bias was corrected by setting the actual threshold to $\mathrm{m}-2 \mathrm{~s}$, where $\mathrm{m}$ and $s$ are the intensity average and standard-deviation, respectively, computed over the nucleus region defined by the preliminary threshold. Holes due mainly to the nucleolus, boundary irregularities due to noise, and bumps due to blur from chromocenters [22] were smoothed out using hole filling, opening, and closing binary morphological operators [23]. Finally, a surface model of the nuclear envelope was generated by applying the marching cubes algorithm [24] to the nucleus binary mask.

\section{Nucleus morphological analysis}

Nucleus size was quantified from the equivalent spherical diameter, i.e., the diameter of the sphere with the same volume as that enclosed by the nuclear surface. Nucleus global shape was quantified using the compactness parameter: Compactness $=36 \pi$ volume $2 /$ surface area ${ }^{3}$.

This parameter, which is comprised between 0 and 1, characterizes shape regularity and takes its maximum value for a sphere. To quantify an eventual flattening of the nucleus, a flatness parameter was derived from the lengths of the principal axes of the nuclear surface: Flatness = length of intermediate axis/length of shortest axis. Flatness was only computed over the nuclei for which the shortest axis corresponded to the $\mathrm{Z}$ (optical axis) direction.

Morphological parameters measured on isolated nuclei before or after FISH were compared to measures made on nuclei from leaf sections with the Mann-Whitney test (alpha $=5 \%$ ) using the R statistical software [25].

\section{Discussion}

Different parameters were chosen and tested to set up the FISH protocol on isolated nuclei and leaf cryosections. Paraformaldehyde fixative was selected over other fixatives because it was previously demonstrated to better preserve chromatin structure and nuclear morphology [2628 ]. The fixation time was optimized to find a compromise between the preservation of the morphology and the extensive cross-linking of the proteins surrounding the DNA. Indeed cross-linking of chromatin complexes masks the availability of the target DNA to labeled probes, requiring harsh permeabilization procedures that could compromise the preservation of nuclei 3D structure for hybridization.

Triton X-100 combined with saponin and additional treatments such as repeated freeze thawing in liquid nitrogen were previously used to permeabilize human and mouse cell nuclei $[4,26,29,30]$. In these studies, an overall conservation of nuclear morphology and chromatin structure was reported. Based on these previous studies, we tested different detergents, triton X-100, saponin and lipsol, individually and combined, at various times and concentrations. Triton X-100 allowed an efficient lysis of chloroplasts and maximized the removal of cytoplasm from both sections and isolated nuclei. With triton X-100, we obtained good quality FISH signals whereas with saponin and lipsol the nuclei were poorly preserved and we obtained weak signals or no signal.

Specimen treatment by $\mathrm{HCl}$ is widely used in FISH protocols for animal and plant cells and tissues [29-31]. It favors probe penetration, thus improving the signal to noise ratio. We observed brighter FISH signals from $\mathrm{HCl}$ treated leaf cryosections than from untreated cryosections, which either yielded faint signals or no signal.

Indirect probe labeling is the most commonly used labeling in plant FISH protocols $[11,12,17]$. We chose direct labeling, since it shortened the procedure and led to to a better sample preservation. Indeed the samples went through fewer steps for signal detection (eg. no incuba- 
tion with primary and fluorescent conjugated antibodies and no subsequent washes). Furthermore, compared to nick translation, random primers labeling yielded higher incorporation rates of the fluorochrome and generated smaller size fragments, favoring probe penetration [32].

Most protocols published thus far use either $80^{\circ} \mathrm{C}$ or higher temperatures for denaturation (e. g. $85^{\circ} \mathrm{C}$, $\left.94^{\circ} \mathrm{C}\right)[4,13,33]$. In this study, thermal denaturation of Arabidopsis nuclei was performed at $70^{\circ} \mathrm{C}, 75^{\circ} \mathrm{C}, 88^{\circ} \mathrm{C}$ and $94^{\circ} \mathrm{C}$ in $50 \%$ formamide hybridization buffer. After FISH, DAPI staining was performed and nuclei were analyzed. A denaturation temperature of $75^{\circ} \mathrm{C}$ was retained for the protocol because at $75^{\circ} \mathrm{C}$ the nuclear structure with the typical compact and well-defined centromeres was maintained and a high quality hybridization signal was observed.
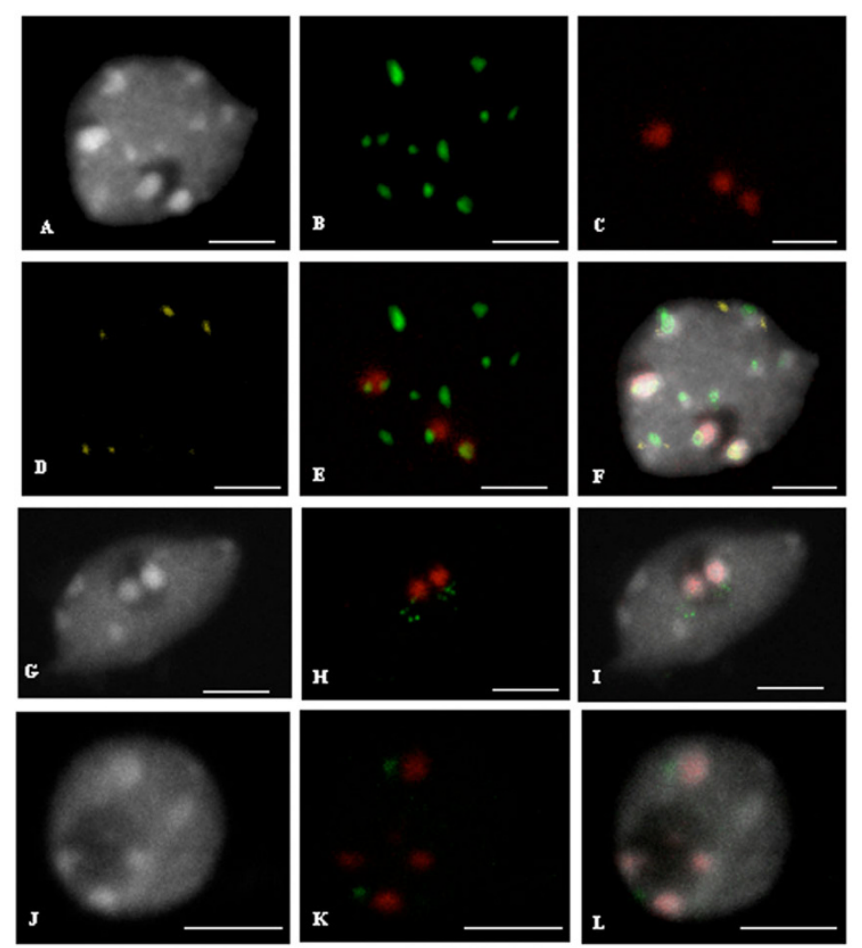

Figure I

FISH on isolated interphase nuclei. (A, G, J) DAPI staining. (B) centromeric 180 bp repeats (Alexa Fluor ${ }^{\circledR}$ 488-5dUT, green). (C) 45S rDNA (Cy5-dUTP, red). (D) $5 \mathrm{~S}$ rDNA (Cy3-dUTP, yellow) (E) Merge with 180 bp repeats and 45S rDNA visible as green and red, respectively. (F) Merge with DAPI, 180 bp repeats, $45 \mathrm{~S}$ rDNA and $5 \mathrm{~S}$ rDNA. Bar $=2 \mu \mathrm{m}$. (H) FISH with 45S rDNA and TIJI BAC specific of chromosome 4 , visible as red and green signals, respectively. (I) Merge. Bar $=4 \mu \mathrm{m}$. (J, K, L) FISH on an isolated interphase nucleus. (J) DAPI. (K) 45S rDNA and BAC T6P5 specific of chromosome 2, visible as red and green, respectively. (L) Merge. Bar $=2 \mu \mathrm{m}$. All images are maximum projections of confocal image stacks.
Representative FISH signals from isolated nuclei labeled with repetitive sequences or BACs specific for chromosomes 2 and 4 are presented in Figure 1. To retain nuclei within the context of their intact tissue environment and keep information on their cellular identity, we developed FISH on leaf cryosections, choosing centromeric repetitive sequences to set up the technique (Figure 2). This technique has the advantage over other embedding techniques using paraffin or resin to be possibly coupled with FISH without dehydration procedures. Indeed, dehydration procedures were shown to negatively affect nuclei morphology [16]. Our FISH protocol combines preservation of nuclear architecture and high resolution imaging of cell nuclei.

Three morphological parameters were used to investigate whether the protocol preserves the overall 3D structure of nuclei, using DAPI stained nuclei from leaf cryosections that have not been FISH treated as reference nuclei. Indeed, because the cell nuclei are embedded within the tissues, their morphology likely closely reflects their in vivo morphology. Table 1 compares the morphological parameters measured on isolated nuclei before and after FISH procedures to reference nuclei from untreated leaf
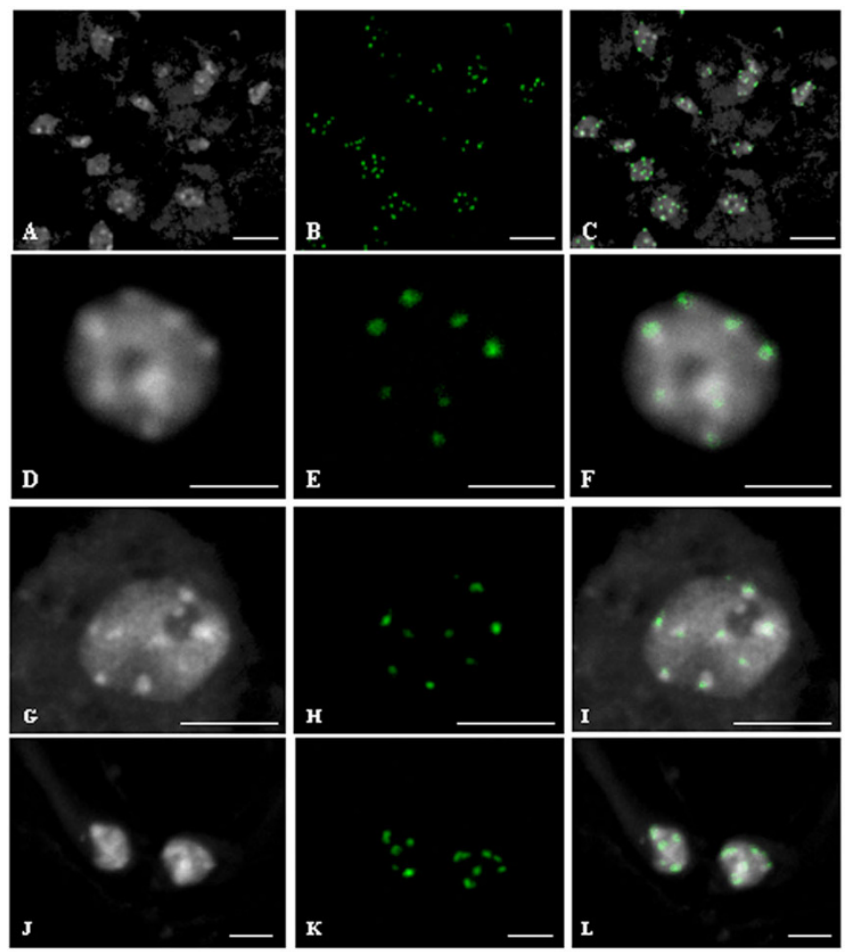

Figure 2

FISH localization of centromeric 180 bp repeats on $20 \mu \mathbf{m}$ cryosections. (A, D, G, J) DAPI counterstaining. (B, $E, H, K$ ) localization of $I 80$ bp repeats. (C, $F, I, L)$ merged images. $(A, B, C)$ cryosection. Bar $=10 \mu \mathrm{m}$. (D, E, F) Epidermis nucleus. Bar $=5 \mu \mathrm{m}$. (G, $\mathrm{H}, \mathrm{I})$ Subepidermis nucleus. Bar $=5 \mu \mathrm{m}$. (J, K, L). Guard cell nuclei. Bar $=2 \mu \mathrm{m}$. 
Table I: Morphological parameters of isolated nuclei before and after FISH treatments compared to untreated nuclei from leaf cryosections.

\begin{tabular}{llllll}
\hline & $N$ & Diameter $(\mu \mathrm{m})$ & Compactness & NZ & Flatness \\
\hline Untreated & 65 & $5.99 \pm 0.72$ & $0.79 \pm 0.07$ & 21 & $1.54 \pm 0.36$ \\
\hline Before FISH & 77 & $5.85 \pm 0.85(p=0.25)$ & $0.77 \pm 0.11(p=0.72)$ & 71 & $1.56 \pm 0.40(p=0.87)$ \\
\hline After FISH & 64 & $5.79 \pm 0.83(p=0.14)$ & $0.74 \pm 0.14(p=0.36)$ & 48 & $1.79 \pm 0.53(p=0.08)$ \\
\hline
\end{tabular}

$\mathrm{N}$ : number of analyzed nuclei; NZ: number of nuclei with the shortest axis aligned with the Z-axis and used to compute flatness. The p-values of the pair wise comparisons between isolated nuclei and untreated cryosection nuclei are given in parenthesis. \pm : Standard error. Untreated: cryosections.

cryosections. No difference in either size or shape, as quantified by the equivalent spherical diameter and compactness, respectively, was noted. In all three groups, most of the nuclei had their shortest axis close to the $\mathrm{Z}$ direction (see column NZ). However, there was no flatness difference, either before or after FISH, with the reference nuclei. Overall, this quantitative morphological analysis strongly suggests that the $3 \mathrm{D}$-FISH protocol preserves nucleus size and shape.

\section{Conclusion}

Although 3D-FISH protocols are widely used to characterize nuclear architecture and dynamics in conjunction with changes in gene expression in animal models, few studies have been performed in plants. In the present work, we report a protocol for the isolation of 3D preserved nuclei and cryosections of Arabidopsis tissues coupled with a direct labeling FISH procedure. Measurement of morphological parameters and statistical analyses indicated that the 3D nuclear morphology was preserved after the FISH procedure, thus validating the protocol. To our knowledge, cryosectioning of Arabidopsis tissues was not previously coupled with FISH and therefore this protocol provides a valuable alternative to other 3D-FISH protocols based on vibratome-sectioned or whole mount specimens to study cell nuclei with defined cell identities $[10,12]$.

\section{Competing interests}

The authors declare that they have no competing interests.

\section{Authors' contributions}

LT and VG designed the experiments. LT did the experiments and drafted the manuscript. PA and EB did confocal images processing and analyses. All authors contributed to the writing and approved the manuscript.

\section{Acknowledgements}

We are grateful to O. Grandjean, L. Gissot and the Laboratoire Commun de Cytologie (INRA, Versailles, France) for the imaging facilities. We thank Allison Mallory for careful reading of the manuscript and Nicole HoubaHérin for her precious support and help. We thank the Région lle-deFrance for the funding of the TCS SP2 AOBS. LT was funded by an INRA post-doctoral fellowship. EB, PA, YM and VG were funded by an INRA agroBI Research Program (2006-2008).

\section{References}

I. Cremer T, Cremer M, Dietzel S, Muller S, Solovei I, Fakan S: Chromosome territories - a functional nuclear landscape. Curr Opin Cell Biol 2006, I 8(3):307-316.

2. Branco MR, Pombo A: Chromosome organization: new facts, new models. Trends Cell Biol 2007, I7(3): I27-134.

3. Khalil A, Grant JL, Caddle LB, Atzema E, Mills KD, Arneodo A: Chromosome territories have a highly nonspherical morphology and nonrandom positioning. Chromosome Res 2007, I5(7):899-916.

4. Gué M, Sun JS, Boudier T: Simultaneous localization of MLL, AF4 and ENL genes in interphase nuclei by 3D-FISH: MLL translocation revisited. BMC Cancer 2006, 6:20.

5. Stadler S, Schnapp V, Mayer R, Stein S, Cremer C, Bonifer C, Cremer T, Dietzel S: The architecture of chicken chromosome territories changes during differentiation. BMC Cell Biol 2004, 5(I):44.

6. Parada LA, McQueen PG, Misteli T: Tissue-specific spatial organization of genomes. Genome Biol 2004, 5(7):R44.

7. Weierich C, Brero A, Stein S, von Hase J, Cremer C, Cremer T, Solovei I: Three-dimensional arrangements of centromeres and telomeres in nuclei of human and murine lymphocytes. Chromosome Res 2003, II(5):485-502.

8. Tessadori F, van Driel R, Fransz P: Cytogenetics as a tool to study gene regulation. Trends Plant Sci 2004, 9(3): 147-153.

9. Lysak M, Fransz P, Schubert I: Cytogenetic analyses of Arabidopsis. In Methods Mol Biol: Arabidopsis protocols Volume 323. 2nd edition. Edited by: Salinas J, Sanchez-Serrano JJ. Humana press Inc Totowa, NJ; 2006: $173-186$.

10. Berr A, Schubert I: Interphase chromosome arrangement in Arabidopsis thaliana is similar in differentiated and meristematic tissues and shows a transient mirror symmetry after nuclear division. Genetics 2007, 1 76(2):853-863.

II. Pecinka A, Kato N, Meister A, Probst AV, Schubert I, Lam E: Tandem repetitive transgenes and fluorescent chromatin tags alter local interphase chromosome arrangement in Arabidopsis thaliana. J Cell Sci 2005, I I 8( I6):375I-3758.

12. Prieto P, Moore G, Shaw P: Fluorescence in situ hybridization on vibratome sections of plant tissues. Nat Protoc 2007, 2(7): $1831-1838$.

13. Costa S, Shaw P: Chromatin organization and cell fate switch respond to positional information in Arabidopsis. Nature 2006, 439(7075):493-496.

14. Santos AP, Wegel E, Allen GC, Thompson WF, Stoger E, Shaw P, Abranches R: In situ Methods to localize transgenes and transcripts in interphase nuclei: a tool for transgenic plant research. Plant Methods 2006, 2:18.

15. Kozubek S, Lukasova E, Amrichova J, Kozubek M, Liskova A, Slotova $\mathrm{J}$ : Influence of cell fixation on chromatin topography. Anal Biochem 2000, 282(I):29-38.

16. Shichiri M, Fukushi D, Sugiyama S, Yoshino T, Ohtani T: Analysis by atomic force microscopy of morphological changes in barley chromosomes during FISH treatment. Chromosome Res 2003, II(I):65-7I. 
17. Tessadori F, Chupeau MC, Chupeau Y, Knip M, Germann S, van Driel $R$, Fransz $P$, Gaudin V: Large-scale dissociation and sequential reassembly of pericentric heterochromatin in dedifferentiated Arabidopsis cells. J Cell Sci 2007, I 20(7): | 200-I 208.

18. Pecinka A, Schubert V, Meister A, Kreth G, Klatte M, Lysak MA, Fuchs J, Schubert I: Chromosome territory arrangement and homologous pairing in nuclei of Arabidopsis thaliana are predominantly random except for NOR-bearing chromosomes. Chromosoma 2004, I I 3(5):258-269.

19. Lysak MA, Pecinka A, Schubert I: Recent progress in chromosome painting of Arabidopsis and related species. Chromosome Res 2003, I I (3): 195-204.

20. Andrey P, Maurin Y: Free-D: an integrated environment for three-dimensional reconstruction from serial sections. J Neurosci Methods 2005, I 45(I-2):233-244.

21. Ridler T, Calvard S: Picture thresholding using an interactive selection method. IEEE Transactions on Systems, Man and Cybernetics 1978, 8:630-632.

22. Ronneberger O, Baddeley D, Scheipl F, Verveer PJ, Burkhardt H, Cremer C, Fahrmeir L, Cremer T, Joffe B: Spatial quantitative analysis of fluorescently labeled nuclear structures: problems, Methods, pitfalls. Chromosome Res 2008, 16(3):523-562.

23. Soille P: Morphological image analysis: Principles and applications 2 nd edition. Berlin: Springer Verlag; 2003.

24. Lorensen $\mathrm{W}$, Cline $\mathrm{H}$ : Marching cubes: a high resolution (3D) surface construction algorithm. AMC Computer Graphics 1987, 2I(4):163-169.

25. R Development Core Team R: A Language and Environment for Statistical Computing. 2007 [http://www.R-project.org]. R Foundation for Statistical Computing Vienna, Austria

26. Hepperger C, Otten S, von Hase J, Dietzel S: Preservation of largescale chromatin structure in FISH experiments. Chromosoma 2007, I 16(2): I I7-133.

27. Shelby RD, Hahn KM, Sullivan KF: Dynamic elastic behavior of alpha-satellite DNA domains visualized in situ in living human cells. J Cell Biol 1996, I35(3):545-557.

28. Solovei I, Cavallo A, Schermelleh L, Jaunin F, Scasselati C, Cmarko D, Cremer C, Fakan S, Cremer T: Spatial preservation of nuclear chromatin architecture during three-dimensional fluorescence in situ hybridization (3D-FISH). Exp Cell Res 2002, 276(I): 10-23.

29. Bolzer A, Kreth G, Solovei I, Koehler D, Saracoglu K, Fauth C, Muller S, Eils R, Cremer C, Speicher MR, Cremer T: Three-dimensional maps of all chromosomes in human male fibroblast nuclei and prometaphase rosettes. PLoS Biol 2005, 3(5):el57.

30. Mongelard F, Vourc'h C, Robert-Nicoud M, Usson Y: Quantitative assessment of the alteration of chromatin during the course of FISH procedures. Fluorescent in situ hybridization. Cytometry 1999, 36(2):96-10I.

31. Jolly C, Mongelard F, Robert-Nicoud M, Vourc'h C: Optimization of nuclear transcript detection by FISH and combination with fluorescence immunocytochemical detection of transcription factors. J Histochem Cytochem 1997, 45( I 2): 1585-1592.

32. Thomas-Cavallin M, Ait-Ahmed O: The random primer labeling technique applied to in situ hybridization on tissue sections. J Histochem Cytochem 1988, 36( I 0): 1335-1340.

33. Celeda D, Aldinger K, Haar FM, Hausmann M, Durm M, Ludwig H, Cremer C: Rapid fluorescence in situ hybridization with repetitive DNA probes: quantification by digital image analysis. Cytometry 1994, 17(1):13-25.
Publish with Biomed Central and every scientist can read your work free of charge

"BioMed Central will be the most significant development for disseminating the results of biomedical research in our lifetime. "

Sir Paul Nurse, Cancer Research UK

Your research papers will be:

- available free of charge to the entire biomedical community

- peer reviewed and published immediately upon acceptance

- cited in PubMed and archived on PubMed Central

- yours - you keep the copyright

Submit your manuscript here:

http://www.biomedcentral.com/info/publishing_adv.asp
BioMedcentral 